\title{
ANALISA POSTUR KERJA DENGAN METODE RAPID UPPER LIMB ASSESSMENT (RULA) PADA OPARATOR MESIN EXTRUDER DI STASIUN KERJA EXTRUDING PADA PT XYZ
}

\author{
Irfan Syah Aji Wijaya, Ahmad Muhsin \\ Jurusan Teknik Industri, Fakultas Teknik Industri \\ Universitas Pembangunan Nasional "Veteran" Yogyakarta \\ Jl. Babarsari 2 Tambakbayan, Yogyakarta, 55281 \\ Telp. (0274) 485363 Fax.: (0274) 486256
}

\begin{abstract}
Abstrak
PADA PT XYZ merupakan produsen makanan ringan terkemuka yang ada di Indonesia. Divisi snack Garing adalah salah satu divisi produksi yang ada di PADA PT XYZ memiliki masalah pada bagian Extrude, dimana operator mesin yang tidak bisa memasukan adoan secara teratur kedalam mesin yang membuat hasil pilus menjadi jelek, tidak bulat sempurna dan cenderung gampang menggumpal saat digoreng. Salah satu faktor yang menyebabkan hal tersebut adalah postur operator yang berpengaruh terhadap kenyamanan dan mudah lelahnya operator

Metode dalam analisis posteur kerja yang digunakan adalah Rapid Upper Limb Assessment (RULA) untuk mengetahui tingkat bahaya pada postur kerja operator serta membandingkan posisi operator saat mengambil dan memasukan adonan kedalam mesin Extruder baik itu dalam posisi duduk dan dalam posisi berdiri. Metode RULA menganalisis postur, gaya, dan gerakan suatu aktifitas yang dapat menyelidiki tingkat resiko yang dihasilkan oleh aktifitas tersebut.

Hasil dari analisis posturkerja menggunakan metode Rapid Upper Limb Assessment (RULA) diketahui bahwa posisi duduk operator yaitu posisi $1 A$, dan $1 B$ serta posisi berdiri operator yaitu posisi $2 A$ dab $2 B$ pada saat mengambil dan memasukan adonan kedalam mesin Extruder, semuanya memiliki nilai final 7 dan action level 4 yang menunjukan menunjukkan bahwa penyelidikan dan perubahan dibutuhkan sesegera mungkin. Berdasarkan analisis metode RULA dapat disimpulkan bahwa penyebab mudah pegal dan lelahnya operator yang mengoprasikan mesin Extruder adalah karena postur kerja yang kurang ergonomis sehingga menurunkan tingkat keteraturan operator dalam memasukan adonan kemesin yang dapat menurunkan kualitas produksi.
\end{abstract}

Kata kunci: Rapid Upper Limb Assessment (RULA), Postur Kerja, Ergonomis

\section{PENDAHULUAN}

PADA PT XYZ merupakan produsen makanan ringan terkemuka yang ada di Indonesia. PADA PT XYZ beralamat di Jalan Pati-Kudus KM. 6,3 Kabupaten Pati Jawa Tengah Indonesia. PADA PT XYZ selalu menjaga mutuproduksinya dengan mengatur standar-standar dalam proses produksinya apalagi dengan selogan PADA PT XYZ tahun 2018 yaitu "SIAP MUTU" yang berarti PT XYZ peduli mutu. Standar mutu yang diterapkan di PT XYZ diterapkan mulai dari pemilihan bahan baku dan di setiap tahap proses produksi, serta dilakukan dengan penuh tanggung jawab dan sepenuh hati oleh seluruh karyawan dan para pekerja.

Divisi snack Garing adalah salah satu divisi produksi yang ada di PT XYZ. Divisi snack Garing mengurusi bagian produksi snack pilus dengan dua merek dagang yaitu Garing dan Pilus. Mesin Extrude berperan penting dalam pembentukan adonan menjadi butiran-butiran pilus yang kecil-kecil dan bulat sempurna. Masalah yang biasa terjadi pada pengoprasian mesin Extrude diantaranya adalah adonan yang tidak sesuai standar dan pememasukan adonan kedalam mesin yang tidak teratur. Adonan yang tidak sesuai standar membuatnya suasah untuk dibentuk serta operator yang tidak bisa memasukan adoan secara teratur akan mengakibatkan adanya celah adonan dalam mesin sehingga membuat hasil pilus menjadi jelek, tidak bulat sempurna dan cenderung gampang menggumpal saat digoreng.

Posisi pekerja dalam memasukan adonanlah yang biasa menjadi faktor yang membuat pekerja tidak bisa teratur memasukan adonan. Posisi pekerja yang bermacam macam baik dengan duduk atau berdiri tidak diketahui apakah posisi mereka sudah tepat, nyaman, dan sehat atau tidak, yang mana apabila tidak akan membuat pekerja cepat lelah dan pegal sehingga membuat mereka tidak teratur dalam memasukan adonan kedalam mesin.

Penelitian ini menganalisis permasalahan diatas menggunakan pengukuran kerja yang didasarkan pada prinsip-prinsip biomekanika, dan salah satu metode yang bisa digunakan yaitu metode Rapid Upper Limb Assessment (RULA) 
untuk mengetahui tingkat bahaya pada posturkerja operator serta membandingkan posisi operator saat mengambil dan memasukan adonan kedalam mesin Extruder baik itu dalam posisi duduk dan dalam posisi berdiri. Metode RULA menganalisis postur, gaya, dan gerakan suatu aktifitas yang dapat menyelidiki tingkat resiko yang dihasilkan oleh aktifitas tersebut.

\section{LANDASAN TEORI \\ Biomekanika}

Dalam dunia industri performansi kerja para karyawan merupak hal yang sangat penting diperhatikan, hal ini dikarenakan performansi kerja merupakan faktor penting dalam proses produksi (Shelfian dkk, 2016). Biomekanika merupakan cabang hasil penelitian ergonomi. Biomekanika menggambarkan beban yang dibawa pekerja dan meminimumkannya sehingga dapat mengurani kecelakaan dan kesehatan kerja. Biomekanika mengukur kekuatan fisik yang dimiliki tenaga kerja seperti kekuatan daya fisik dan kemampuan tubuh manisia secara mekanis pada saat melakukan aktivitas dan cara kerja serta fasilitas dan peralatan dirancang agar sesuai dengan kemampuan tubuh manusia ketika melakukan pekerjaan. (Afriansyah, 2015) .

\section{Postur Kerja}

Postur kerja adalah sikap tubuh saat bekerja. Sikap kerja yang berlainan akan menghasilkan kekuatan yang berbeda. Pada saat bekerja postur dilakukan dirancang agar terjadi alamiyah sehingga dapat mengurangi timbulnya cedera muscoluskeletal (Masitoh, 2016). Kenyamanan terwujud apabila pekerja melakukan postur kerja yang sesuai dan nyaman. Dalam tubuh manusia terdapat jenis gaya, yaitu (Masitoh, 2016) :

1. Gaya gravitasi, yaitu gaya yang melalui pusat massa dari tiap segmen tubuh manusia dengan arah kebawah ( $\mathrm{F}=\mathrm{m} . \mathrm{g})$.

2. Gaya Reaksi, yaitu gaya yang terjadi akibat beban pada segmen tubuh atau berat segmen tubuh itu sendiri.

3. Gaya otot, yaitu gaya yang terjadi pada bagian sendi, baik akibat gesekan sendi atau akibat gaya pada otot yang melekat pada sendi.

Gaya ini menggambarkan besarnya gaya momen otot.

4. Gaya otot, yaitu gaya yang terjadi pada bagian sendi, baik akibat gesekan sendi atau akibat gaya pada otot yang melekat pada sendi. Gaya ini menggambarkan besarnya gaya momen otot.

Tubuh manusia terdiri dari 6 link yaitu (Masitoh, 2016):

1. Link lengan bawah, dibatasi joint telapak tangan dan siku.

2. Link lengan atas, dibatasi joint siku dan bahu.

3. Link punggung, dibatasi joint bahu dan pinggul.

4. Link paha, dibatasi joint pinggul dan lutut.

5. Link betis, dibatasi joint lutut dan mata kaki.

6. Link kaki, dibatasi joint mata kaki dan telapak kaki.

Pengukuran waktu adalah pekerjaan mengamati dan mencatat waktu-waktu kerjanya baik setiap elemen ataupun siklus dengan menggunakan alat-alat yang telah disiapkan (M. Ade Rafian dan Ahmad Muhsin, 2017).

Postur kerja yang baik sangat ditentukan oleh pergerakan organ tubuh saat bekerja. Pergerakan yang dilakukan saat bekerja meliputi: flexion, extension, abduction, adduction, rotation, pronation dan supination. Flexion adalah gerakan dimana sudut antara dua tulang terjadi pengurangan., extension adalah gerakan merentangkan dimana terjadi peningkatan sudut antara dua tulang. abduction adalah gerakan menyamping menjauhi dari sumbu tengah tubuh. Adduction adalah pergerakan kearah sumbu tengah tubuh. Rotation adalah perputaran bagian atas lengan atau kaki depan. Pronation adalah perputaran bagian tengah (menuju kedalam) dari anggota tubuh. Supination adalah perputaran kea rah samping (menuju luar) dari anggota tubuh (Rinawati dan Romadona, 2016).

\section{Comulative Trauma Disordersadlah}

Comulative Trauma Disordersadlah cidera pada system kerangka otot yang semakin bertambah secara bertahap sebagai akibat dari trauma kecil yang terus menerus yang disebabkan oleh disain yang buruk yaitu disain alat/system kerja yang membutuhkan gerakan tubuh dalam posisi yang tidak normal serta penggunaan perkakas atau alat lainnya terlalu sering (Anjasmoro, 2017), penyebabnya adalah:

1. Penggunaan gaya yang sangat berlebihan selama gerakan normal.

2. Gerakan sendi yang kaku yaitu tidak pada posisi normal

3. Perulangan gerkan yang sama secara terus menerus 
4. Kurangnya istirahat yang cukup untuk memulihkan trauma sendi.

\section{Rapid Upper Limb Assessment (RULA)}

Rapid Upper Limb Assissment (RULA) dikembangkan oleh Dr.Lynn Mc Atamney dan Dr. Nigel Corlett yang merupakan ergonomi dari universitas di Nottingham (University of Nottingham's Institute of Osecupational Ergonomics). Pertama kali dijelaskan dalam bentuk jurnal aplikasi ergonomi pada tahun 1993. RULA adalah metode yang dikembangkan dalam bidang ergonomi yang menginvestigasi dan menilai posisi kerja yang dilakukan oleh tubuh bagian atas. Metode ini tidak membutuhkan piranti khusus dalam memberikan penilaian dalam postur leher, punggung dan tubuh bagian atas (Meliana, 2009).

Sejalan dengan fungsi otot dan beban eksternal yang ditopang oleh tubuh. Teknologi ergonomic tersebut mengevaluasi postur, kekuatan dan aktivitas otot yang menimbulkan cedera akibat aktivitas berulang.RULA dikembangkan untuk mendeteksi postur kerja yang beresiko dan melakukan perbaikan sesegera mungkin (Mc Atamney dan Corlett, 2004). Penilaian menggunakan metode ini adalah metode yang telah dilakukan oleh McAtamey dan Corlett (1993).

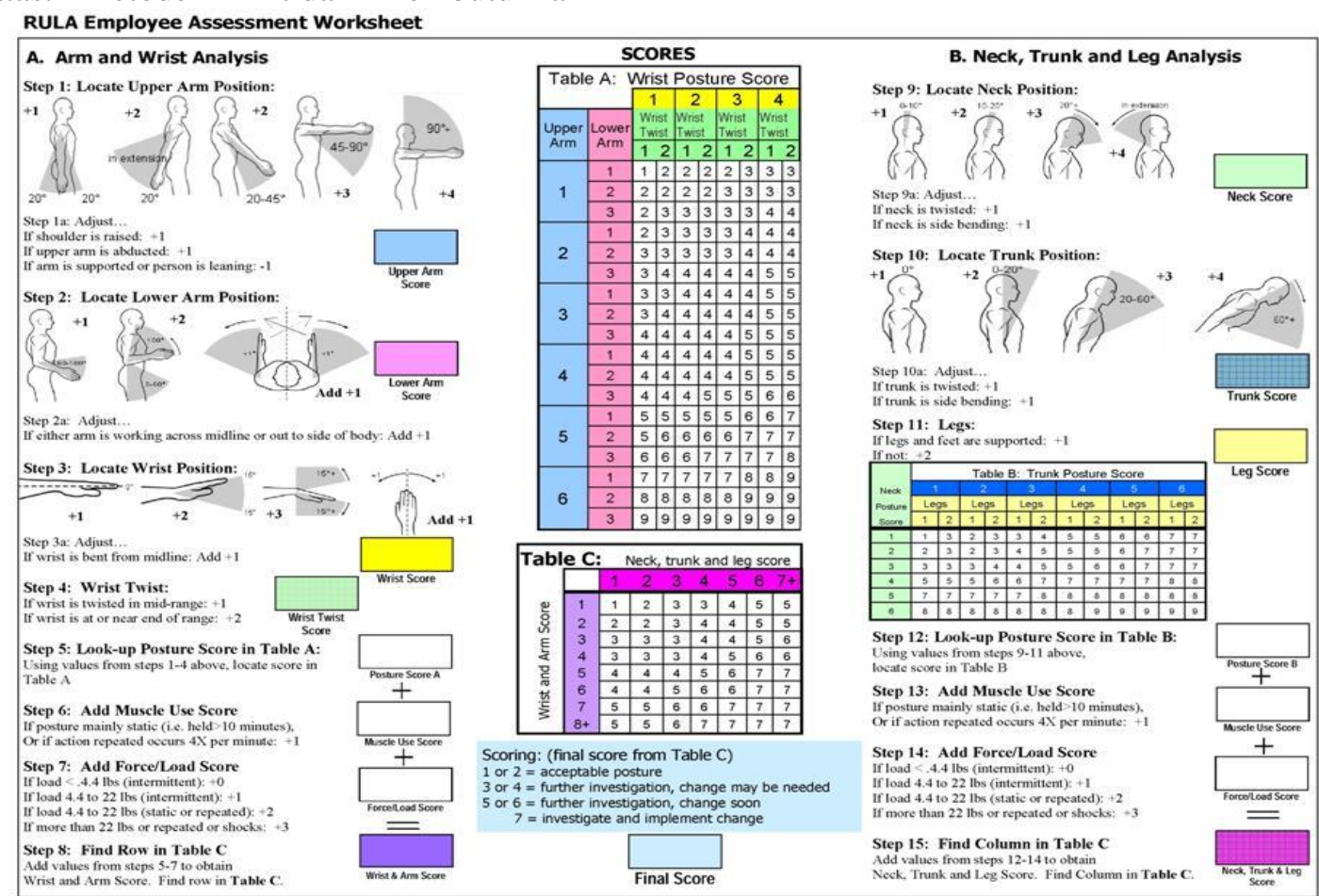

Gambar 2.1 Lembar analisis RULA (sumber : McAtamey dan Corlett ,1993)

\section{METODOLOGI PENELITIAN Metode Pengumpulan Data}

Data yang diguakan dalam penelitian ini terdiri dari:

\section{Data Primer}

Data primer yaitu data yang berasal dari pengamatan dan penelitian yang diperoleh dari objek penelitian di lapangan yaitu kondisi aktual atau nyata dari lantai pabrik, meliputi pengamatan langsung postur kerja operator. Data yang digunakan adalah:

a. Data metode kerja

b. Data postur kerja, berupa foto operator melakukan aktivitas dengan postur kerja tertentu

\section{c. Data waktu postur kerja \\ d. Ukuran fasilitas}

2. Data Sekunder

Data sekunder adalah data yang didapat dari referensi ataupun literaturliteratur yang berhubungan dengan masalah yang diteliti, dan juga data yang didapat dari perusahaan, yaitu gambaran umum dan sejarah perusahaan, jumlah pegawai, organisasi dan manajemen perusahaan.

Langkahh-langkah dalam melakukan analisis postur kerja menggunakan metode Rapid upper limb assessment (RULA) adalah sebagai berikut : 
1. Langkah-langkah dalam melakukan analisis postur kerja menggunakan metode RULA

a. Membagi pengamatan postur tubuh menjadi dua grup, grup A memperlihatkan postur tubuh bagian lengan atas, lengan bawah, pergelangan tangan, dan grup B terdiri dari Leher, punggung dan kaki. Selain itu juga ada pengukuran beban dan skor aktivitas.

b. Menilai setiap postur kerja operstor menggunakan form RULA ke dalam skor A dan B.

c. Menentukan skor akhir RULA dari hasil kombinasi perhitungan skor A dan skor B.

d. Menentukan action level dari postur kerja operator.

\section{PENGOLAHAN DATA}

\section{Pengumpulan Data}

Pengumpulan Data Sketsa Gambar Posisi Operator Mesin Extruder.

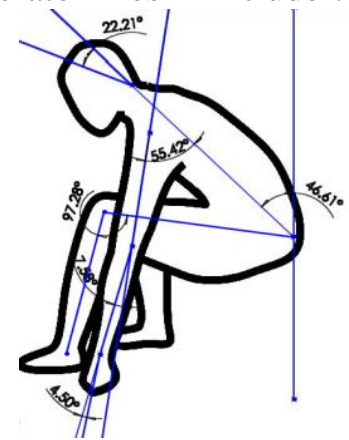

Gambar 4.6 Garis posisi 1A

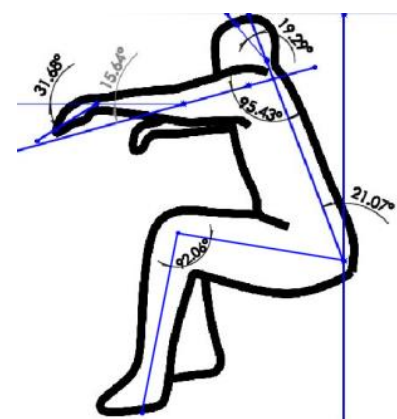

Gambar 4.7 Garis posisi 1B

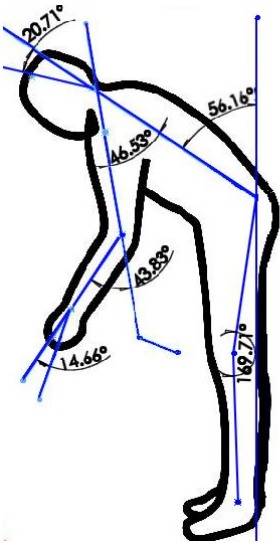

Gambar 4.8 Garis posisi 2A

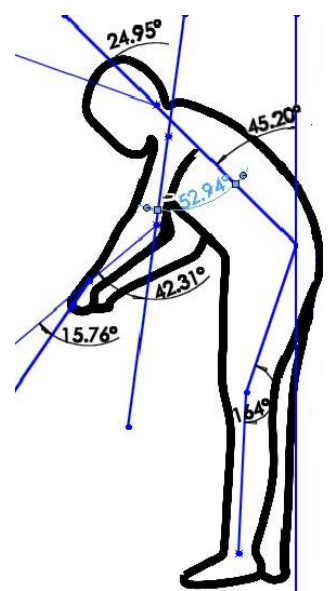

Gambar 4.9 Garis posisi 2B

Pengolahan Data

Perhitungan Skor Postur Kerja Posisi 1A

Tabel 4.1 Sudut posisi 1A

\begin{tabular}{|c|c|c|}
\hline Sudut & $\begin{array}{c}\text { Postur } \\
\text { kerja }\end{array}$ & Nilai \\
\hline Leher & $22,21^{\circ}$ & 3 \\
\hline Punggung & $46,61^{\circ}$ & 4 \\
\hline Lengan atas & $55,42^{\circ}$ & 3 \\
\hline $\begin{array}{c}\text { Lengan } \\
\text { bawah }\end{array}$ & $7,58^{\circ}$ & 3 \\
\hline Pergelangan & $4,50^{\circ}$ & 2 \\
\hline
\end{tabular}

Postur tubuh grup A

a. Wrist Twist : Pergelangan tangan berada dalam kisaran putaran, maka diberi nilai 1

Tabel 4.2 RULA skor grup A posisi 1A

\begin{tabular}{|c|c|c|c|c|c|}
\hline Lenga & Lenga & \multicolumn{4}{|c|}{ Pergelangan tangan } \\
\cline { 3 - 6 } n atas & $\mathrm{n}$ & 1 & 2 & 3 & 4 \\
\cline { 3 - 6 } & bawah & Wri & Wri & Wri & Wri \\
& & st & st & st & st \\
\hline
\end{tabular}




\begin{tabular}{|c|c|c|c|c|c|c|c|c|c|}
\hline \multirow{2}{*}{} & & \multicolumn{2}{c|}{$\begin{array}{c}\text { Twi } \\
\text { st }\end{array}$} & \multicolumn{2}{c|}{$\begin{array}{c}\text { Twi } \\
\text { st }\end{array}$} & \multicolumn{2}{c|}{ Twi } \\
st
\end{tabular}

b. Otot : Pekerja melakukan kegiatan 4 kali/menit, sesuai dengan penilaian otot diberi nilai 1

c. Beban : Pembebanan statis $2-10 \mathrm{~kg}$ atau berulang, diberi nilai 2

d. Total Skor postur tubuh A adalah : $4+$ $1+2=7$

Postur tubuh grup B

a. Kaki : pekerja dalam keadaan duduk dan kaki tertopang dengan baik, maka diberi nilai 1

Tabel 4.3 RULA skor grup B posisi 1A

\begin{tabular}{|c|c|c|c|c|c|c|c|c|c|c|c|c|}
\hline & & & 2 & & 3 & & & & 5 & & 6 & \\
\hline & $\mathrm{K}$ & & $\mathrm{K}$ & & $\mathrm{Ka}$ & & K & & $\mathrm{Ka}$ & & $\mathrm{Ka}$ & \\
\hline Leh & 1 & 2 & 1 & 2 & & 2 & 1 & 2 & 1 & 2 & & 2 \\
\hline er & & & & & & & & & & & & \\
\hline 1 & 1 & 3 & 2 & 3 & 3 & 4 & 5 & & 6 & 5 & 7 & 7 \\
\hline 2 & 2 & 3 & 2 & 3 & 4 & 5 & 5 & 5 & 6 & 7 & 7 & 7 \\
\hline 3 & 3 & 3 & 3 & 4 & 4 & 5 & 5 & 6 & 6 & 7 & 7 & 7 \\
\hline 4 & 5 & 5 & 5 & 6 & 6 & 7 & 7 & & 7 & 7 & 8 & 8 \\
\hline 5 & 7 & 7 & 7 & 7 & 7 & 8 & 8 & & 8 & 8 & 8 & 8 \\
\hline 6 & 8 & 8 & 8 & 8 & 8 & 8 & 8 & 9 & 9 & & & 9 \\
\hline
\end{tabular}

b. Otot : Pekerja melakukan kegiatan 4 kali/menit, maka sesuai dengan penilaian otot diberi nilai 1 c. Beban/ Tenaga : Pembebanan statis 2-10 $\mathrm{kg}$ atau berulang, maka diberi nilai 2

d. Total Skor postur tubuh B adalah $5+1+2=8$

Final score

Tabel 4.4 RULA final score posisi 1A

\begin{tabular}{|c|c|c|c|c|c|c|c|c|}
\hline & \multicolumn{10}{|c|}{ Nilai A } \\
\hline \multirow{4}{*}{} & & $\mathbf{1}$ & $\mathbf{2}$ & $\mathbf{3}$ & $\mathbf{4}$ & $\mathbf{5}$ & $\mathbf{6}$ & $\mathbf{7 +}$ \\
\cline { 2 - 9 } & $\mathbf{1}$ & 1 & 2 & 3 & 3 & 4 & 5 & 5 \\
\cline { 2 - 9 } & $\mathbf{2}$ & 2 & 2 & 3 & 4 & 4 & 5 & 5 \\
\cline { 2 - 8 } & $\mathbf{3}$ & 3 & 3 & 3 & 4 & 4 & 5 & 6 \\
\cline { 2 - 8 } & $\mathbf{4}$ & 3 & 3 & 3 & 4 & 5 & 6 & 6 \\
\cline { 2 - 8 } & $\mathbf{5}$ & 4 & 4 & 4 & 5 & 6 & 7 & 7 \\
\cline { 2 - 8 } & $\mathbf{6}$ & 4 & 4 & 5 & 6 & 6 & 7 & 7 \\
\cline { 2 - 8 } & $\mathbf{7}$ & 5 & 5 & 6 & 6 & 7 & 7 & 7 \\
\cline { 2 - 8 } & $\mathbf{8 +}$ & 5 & 5 & 6 & 7 & 7 & 7 & 7 \\
\hline
\end{tabular}

Berdasarkan tabel diatas maka Skor akhir dari penilaian RULA sebesar 7. Skor 7 masuk kedalam Action Level 4, yang menunjukkan bahwa penyelidikan dan perubahan dibutuhkan sesegera mungkin.

Perhitungan Skor Postur Kerja Posisi 1B Menggunakan RULA

Tabel 4.5 Sudut garis imajiner posisi 1B

\begin{tabular}{|c|c|c|}
\hline Sudut & Postur kerja & Nilai \\
\hline Leher & $19,29^{\circ}$ & 2 \\
\hline Punggung & $21,07^{\circ}$ & 3 \\
\hline Lengan atas & $95,43^{\circ}$ & 4 \\
\hline $\begin{array}{c}\text { Lengan } \\
\text { bawah }\end{array}$ & $15,64^{\circ}$ & 2 \\
\hline Pergelangan & $31,68^{\circ}$ & 3 \\
\hline
\end{tabular}

Postur tubuh grup A

a. Wrist Twist : Putaran pergelangan tangan berada didekat akhir jangkauan, maka diberi nilai 1

Tabel 4.6 RULA skor grup A posisi 1B

\begin{tabular}{|c|c|c|c|c|c|c|c|c|c|}
\hline \multirow{5}{*}{$\begin{array}{l}\text { Lengan } \\
\text { atas }\end{array}$} & \multirow{5}{*}{$\begin{array}{l}\text { Lengan } \\
\text { bawah }\end{array}$} & \multicolumn{8}{|c|}{ Wrist } \\
\hline & & \multicolumn{2}{|c|}{1} & \multicolumn{2}{|c|}{2} & 3 & & 2 & \\
\hline & & \multirow{2}{*}{\multicolumn{2}{|c|}{$\begin{array}{l}\text { Wrist } \\
\text { Twist }\end{array}$}} & \multirow{2}{*}{\multicolumn{2}{|c|}{$\begin{array}{l}\text { Wrist } \\
\text { Twist }\end{array}$}} & & \multicolumn{2}{|c|}{ Wrist } \\
\hline & & & & & & \multicolumn{2}{|c|}{ Twist } & \multicolumn{2}{|c|}{ Twist } \\
\hline & & 1 & 2 & 1 & 2 & 1 & 2 & 1 & 2 \\
\hline \multirow[t]{3}{*}{1} & 1 & 1 & 2 & 2 & 2 & 2 & 3 & 3 & 3 \\
\hline & 2 & 2 & 2 & 2 & 2 & 3 & 3 & 3 & 3 \\
\hline & 3 & 2 & 3 & 3 & 3 & 3 & 3 & 4 & 4 \\
\hline \multirow[t]{3}{*}{2} & 1 & 2 & 3 & 3 & 3 & 3 & 4 & 4 & 4 \\
\hline & 2 & 3 & 3 & 3 & 3 & 3 & 4 & 4 & 4 \\
\hline & 3 & 3 & 4 & 4 & 4 & 4 & 4 & 5 & 5 \\
\hline \multirow[t]{2}{*}{3} & 1 & 3 & 3 & 4 & 4 & 4 & 4 & 5 & 5 \\
\hline & 2 & 3 & 4 & 4 & 4 & 4 & 4 & 5 & 5 \\
\hline
\end{tabular}




\begin{tabular}{|l|l|l|l|l|l|l|l|l|l|}
\hline & 3 & 4 & 4 & 4 & 4 & 4 & 5 & 5 & 5 \\
\hline 4 & 1 & 4 & 4 & 4 & 4 & 4 & 5 & 5 & 5 \\
\cline { 2 - 9 } & 2 & 4 & 4 & 4 & 4 & 4 & 5 & 5 & 5 \\
\cline { 2 - 9 } & 3 & 4 & 4 & 4 & 5 & 5 & 5 & 6 & 6 \\
\hline 5 & 1 & 5 & 5 & 5 & 5 & 5 & 6 & 6 & 7 \\
\cline { 2 - 9 } & 2 & 5 & 6 & 6 & 6 & 6 & 7 & 7 & 7 \\
\cline { 2 - 9 } & 3 & 6 & 6 & 6 & 7 & 7 & 7 & 7 & 8 \\
\cline { 2 - 9 } & & 1 & 2 & 1 & 2 & 1 & 2 & 1 & 2 \\
\hline 6 & 1 & 7 & 7 & 7 & 7 & 7 & 8 & 8 & 9 \\
\cline { 2 - 9 } & 2 & 8 & 8 & 8 & 8 & 8 & 9 & 9 & 9 \\
\cline { 2 - 9 } & 3 & 9 & 9 & 9 & 9 & 9 & 9 & 9 & 9 \\
\hline
\end{tabular}

b. Otot : Pekerja melakukan kegiatan 4 kali/menit, maka sesuai dengan penilaian otot diberi nilai 1

c. Beban/ Tenaga : Pembebanan statis < $2 \mathrm{~kg}$ atau berulang, maka diberi nilai 1

d. Total Skor postur tubuh A adalah $4+1+1=6$

Postur tubuh grup B

a. Kaki : Posisi kaki pekerja dalam keadaan duduk dengan kaki tertopang dengan baik, maka diberi nilai 1

Tabel 4.7 RULA skor grup B posisi 1B

\begin{tabular}{|c|c|c|c|c|c|c|c|c|c|c|c|c|}
\hline \multirow{2}{*}{$\begin{array}{c}\text { Pung } \\
\text { gun } \\
\text { g }\end{array}$} & \multicolumn{2}{c|}{$\begin{array}{c}\text { Kak } \\
\text { i }\end{array}$} & \multicolumn{2}{|c|}{$\begin{array}{c}\text { Kak } \\
\mathrm{i}\end{array}$} & \multicolumn{2}{c|}{$\begin{array}{c}\text { Kak } \\
\mathrm{i}\end{array}$} & \multicolumn{2}{c|}{$\begin{array}{c}\text { Kak } \\
\mathrm{i}\end{array}$} & \multicolumn{2}{c|}{$\begin{array}{c}\text { Kak } \\
\mathrm{i}\end{array}$} & \multicolumn{2}{|c|}{$\begin{array}{c}\text { Kak } \\
\mathrm{i}\end{array}$} \\
\hline $\begin{array}{c}\text { Le } \\
\text { Her }\end{array}$ & 1 & 2 & 1 & 2 & 1 & 2 & 1 & 2 & 1 & 2 & 1 & 2 \\
\hline 1 & 1 & 3 & 2 & 3 & 3 & 4 & 5 & 5 & 6 & 6 & 7 & 7 \\
\hline 2 & 2 & 3 & 2 & 3 & 4 & 5 & 5 & 5 & 6 & 7 & 7 & 7 \\
\hline 3 & 3 & 3 & 3 & 4 & 4 & 5 & 5 & 6 & 6 & 7 & 7 & 7 \\
\hline 4 & 5 & 5 & 5 & 6 & 6 & 7 & 7 & 7 & 7 & 7 & 8 & 8 \\
\hline 5 & 7 & 7 & 7 & 7 & 7 & 8 & 8 & 8 & 8 & 8 & 8 & 8 \\
\hline 6 & 8 & 8 & 8 & 8 & 8 & 8 & 8 & 9 & 9 & 9 & 9 & 9 \\
\hline
\end{tabular}

a. Otot : Pekerja melakukan kegiatan 4 kali/menit, maka sesuai dengan penilaian otot diberi nilai 1

b. Beban/ Tenaga : Pembebanan statis < $2 \mathrm{~kg}$ atau berulang, maka diberi nilai 1

c. Total Skor postur tubuh B adalah $4+1+1=6$

Final score

Tabel 4.8 RULA final score posisi 1B

\begin{tabular}{|c|c|c|c|c|c|c|c|c|}
\hline & \multicolumn{10}{|c|}{ Nilai A } \\
\hline $\mathbf{Z} \cdot-$ & & $\mathbf{1}$ & $\mathbf{2}$ & $\mathbf{3}$ & $\mathbf{4}$ & $\mathbf{5}$ & $\mathbf{6}$ & $\mathbf{7 +}$ \\
\hline
\end{tabular}

\begin{tabular}{|c|c|c|c|c|c|c|c|}
\hline $\mathbf{1}$ & 1 & 2 & 3 & 3 & 4 & 5 & 5 \\
\hline $\mathbf{2}$ & 2 & 2 & 3 & 4 & 4 & 5 & 5 \\
\hline $\mathbf{3}$ & 3 & 3 & 3 & 4 & 4 & 5 & 6 \\
\hline $\mathbf{4}$ & 3 & 3 & 3 & 4 & 5 & 6 & 6 \\
\hline $\mathbf{5}$ & 4 & 4 & 4 & 5 & 6 & 7 & 7 \\
\hline $\mathbf{6}$ & 4 & 4 & 5 & 6 & 6 & 7 & 7 \\
\hline $\mathbf{7}$ & 5 & 5 & 6 & 6 & 7 & 7 & 7 \\
\hline $\mathbf{8}+$ & 5 & 5 & 6 & 7 & 7 & 7 & 7 \\
\hline
\end{tabular}

Berdasarkan tabel diatas maka Skor akhir dari penilaian RULA sebesar 7. Skor 7 masuk kedalam Action Level 4, yang menunjukkan bahwa penyelidikan dan perubahan dibutuhkan sesegera mungkin.

Perhitungan Skor Postur Kerja Posisi 2A Menggunakan RULA

Tabel 4.9 Sudut garis imajiner posisi 2A

\begin{tabular}{|c|c|c|}
\hline Sudut & Postur kerja & \\
\hline Leher & $20,71^{\circ}$ & 3 \\
\hline Punggung & $56,16^{\circ}$ & 4 \\
\hline Lengan atas & $46,53^{\circ}$ & 3 \\
\hline $\begin{array}{c}\text { Lengan } \\
\text { bawah }\end{array}$ & $43,83^{\circ}$ & 2 \\
\hline Pergelangan & $14,66^{\circ}$ & 2 \\
\hline
\end{tabular}

Postur tubuh grup A

a. Wrist Twist : Putaran pergelangan tangan berada didekat akhir jangkauan, maka diberi nilai 1

Tabel 4.10 RULA skor grup A posisi 2A

\begin{tabular}{|c|c|c|c|c|c|c|c|c|c|}
\hline \multirow{7}{*}{$\begin{array}{l}\text { Len } \\
\text { gan } \\
\text { atas }\end{array}$} & \multirow{7}{*}{$\begin{array}{l}\text { Leng } \\
\text { an } \\
\text { baw } \\
\text { ah }\end{array}$} & \multicolumn{8}{|c|}{ Pergelangan tangan } \\
\hline & & \multicolumn{2}{|l|}{1} & \multicolumn{2}{|c|}{2} & \multicolumn{2}{|c|}{3} & \multicolumn{2}{|c|}{4} \\
\hline & & \multirow{4}{*}{\multicolumn{2}{|c|}{$\begin{array}{c}\text { Wris } \\
t \\
\text { Twis }\end{array}$}} & \multirow{3}{*}{\multicolumn{2}{|c|}{$\begin{array}{l}\text { Wrist } \\
\text { Twist }\end{array}$}} & \multirow{3}{*}{\multicolumn{2}{|c|}{$\begin{array}{l}\text { Wrist } \\
\text { Twist }\end{array}$}} & \multirow{2}{*}{\multicolumn{2}{|c|}{$\begin{array}{l}\text { Wris } \\
\text { Twis }\end{array}$}} \\
\hline & & & & & & & & & \\
\hline & & & & & & & & & \\
\hline & & & & & & & & & \\
\hline & & 1 & 2 & 1 & 2 & 1 & 2 & & \\
\hline \multirow[t]{3}{*}{1} & 1 & 1 & 2 & 2 & 2 & 2 & 3 & 3 & 3 \\
\hline & 2 & 2 & 2 & 2 & 2 & 3 & 3 & 3 & 3 \\
\hline & 3 & 2 & 3 & 3 & 3 & 3 & 3 & 4 & 4 \\
\hline \multirow[t]{3}{*}{2} & 1 & 2 & 3 & 3 & 3 & 3 & 4 & 4 & 4 \\
\hline & 2 & 3 & 3 & 3 & 3 & 3 & 4 & 4 & 4 \\
\hline & 3 & 3 & 4 & 4 & 4 & 4 & 4 & 5 & 5 \\
\hline \multirow[t]{3}{*}{3} & 1 & 3 & 3 & 4 & 4 & 4 & 4 & 5 & 5 \\
\hline & 2 & 3 & 4 & 4 & 4 & 4 & 4 & 5 & 5 \\
\hline & 3 & 4 & 4 & 4 & 4 & 4 & 5 & 5 & 5 \\
\hline \multirow[t]{3}{*}{4} & 1 & 4 & 4 & 4 & 4 & 4 & 5 & 5 & 5 \\
\hline & 2 & 4 & 4 & 4 & 4 & 4 & 5 & 5 & 5 \\
\hline & 3 & 4 & 4 & 4 & 5 & 5 & 5 & 6 & 6 \\
\hline \multirow[t]{2}{*}{5} & 1 & 5 & 5 & 5 & 5 & 5 & 6 & 6 & 7 \\
\hline & 2 & 5 & 6 & 6 & 6 & 6 & 7 & 7 & 7 \\
\hline
\end{tabular}




\begin{tabular}{|l|l|l|l|l|l|l|l|l|l|}
\hline & 3 & 6 & 6 & 6 & 7 & 7 & 7 & 7 & 8 \\
\hline \multirow{3}{*}{6} & 1 & 7 & 7 & 7 & 7 & 7 & 8 & 8 & 9 \\
\cline { 2 - 10 } & 2 & 8 & 8 & 8 & 8 & 8 & 9 & 9 & 9 \\
\cline { 2 - 9 } & 3 & 9 & 9 & 9 & 9 & 9 & 9 & 9 & 9 \\
\hline
\end{tabular}

b. Otot : Pekerja melakukan kegiatan 4 kali/menit, maka sesuai dengan penilaian otot diberi nilai 1

c. Beban : Statis $2-10 \mathrm{~kg}$ atau berulang, maka diberi nilai 2

d. Total Skor postur tubuh A adalah $4+1+2=7$

Postur tubuh grup B

a. Kaki : Posisi pekerja dalam keadaan berdiri dengan berat badan terdistribusi dengan rata oleh kedua kaki, terdapat ruang gerak yang cukup untuk merubah posisi, maka diberi nilai 1

Tabel 4.11 RULA skor grup B posisi 2A

\begin{tabular}{|c|c|c|c|c|c|c|c|c|c|c|c|c|}
\hline \multirow{2}{*}{} & \multicolumn{2}{|c|}{1} & \multicolumn{2}{|c|}{2} & \multicolumn{2}{|c|}{3} & \multicolumn{2}{c|}{4} & \multicolumn{2}{|c|}{5} & \multicolumn{2}{c|}{6} \\
\cline { 2 - 13 } & \multicolumn{2}{|c|}{ Kaki } & \multicolumn{2}{|c|}{ Kaki } & \multicolumn{2}{c|}{ Kaki } & \multicolumn{2}{c|}{ Kaki } & \multicolumn{2}{|c|}{ Kaki } & \multicolumn{2}{c|}{ Kaki } \\
\hline ehe & 1 & 2 & 1 & 2 & 1 & 2 & 1 & 2 & 1 & 2 & 1 & 2 \\
\hline 1 & 1 & 3 & 2 & 3 & 3 & 4 & 5 & 5 & 6 & 6 & 7 & 7 \\
\hline 2 & 2 & 3 & 2 & 3 & 4 & 5 & 5 & 5 & 6 & 7 & 7 & 7 \\
\hline 3 & 3 & 3 & 3 & 4 & 4 & 5 & 5 & 6 & 6 & 7 & 7 & 7 \\
\hline 4 & 5 & 5 & 5 & 6 & 6 & 7 & 7 & 7 & 7 & 7 & 8 & 8 \\
\hline 5 & 7 & 7 & 7 & 7 & 7 & 8 & 8 & 8 & 8 & 8 & 8 & 8 \\
\hline 6 & 8 & 8 & 8 & 8 & 8 & 8 & 8 & 9 & 9 & 9 & 9 & 9 \\
\hline
\end{tabular}

b. Berdasarkan langkah 9 - 11, maka didapatkan nilai 5

c. Otot : Pekerja melakukan kegiatan 4 kali/menit, maka sesuai dengan penilaian otot diberi nilai 1

d. Beban/ Tenaga : Pembebanan statis 2$10 \mathrm{~kg}$ atau berulang, maka diberi nilai 2

e. Total Skor postur tubuh B adalah $5+1+2=8$

\section{Final score}

Tabel 4.12 RULA final score posisi 2A

\begin{tabular}{|c|c|c|c|c|c|c|c|c|}
\hline & \multicolumn{7}{|c|}{ Nilai A } \\
\hline \multirow{3}{*}{$\overline{\tilde{\Xi}}$} & & $\mathbf{1}$ & $\mathbf{2}$ & $\mathbf{3}$ & $\mathbf{4}$ & $\mathbf{5}$ & $\mathbf{6}$ & $\mathbf{7 +}$ \\
\cline { 2 - 9 }$\overline{\mathbf{z}}$ & $\mathbf{1}$ & 1 & 2 & 3 & 3 & 4 & 5 & 5 \\
\cline { 2 - 8 } & $\mathbf{2}$ & 2 & 2 & 3 & 4 & 4 & 5 & 5 \\
\cline { 2 - 8 } & $\mathbf{3}$ & 3 & 3 & 3 & 4 & 4 & 5 & 6 \\
\hline
\end{tabular}

\begin{tabular}{|c|c|c|c|c|c|c|c|c|}
\hline $\mathbf{4}$ & 3 & 3 & 3 & 4 & 5 & 6 & 6 \\
\hline $\mathbf{5}$ & 4 & 4 & 4 & 5 & 6 & 7 & 7 \\
\cline { 2 - 7 } & $\mathbf{6}$ & 4 & 4 & 5 & 6 & 6 & 7 & 7 \\
\hline $\mathbf{7}$ & 5 & 5 & 6 & 6 & 7 & 7 & 7 \\
\hline $\mathbf{8 +}$ & 5 & 5 & 6 & 7 & 7 & 7 & 7 \\
\hline
\end{tabular}

Berdasarkan tabel diatas maka Skor akhir dari penilaian RULA sebesar 7. Skor 7 masuk kedalam Action Level 4, yang menunjukkan bahwa penyelidikan dan perubahan dibutuhkan sesegera mungkin.

Perhitungan Skor Postur Kerja Posisi 1A Menggunakan RULA

Tabel 4.13 Sudut garis imajiner posisi 2B

\begin{tabular}{|c|c|c|}
\hline Sudut & $\begin{array}{c}\text { Postur } \\
\text { kerja }\end{array}$ & Nilai \\
\hline Leher & $24,95^{\circ}$ & 3 \\
\hline Punggung & $45,20^{\circ}$ & 4 \\
\hline Lengan atas & $52,94^{\circ}$ & 3 \\
\hline Lengan bawah & $42,31^{\circ}$ & 2 \\
\hline Pergelangan & $15,76^{\circ}$ & 3 \\
\hline
\end{tabular}

Postur tubuh grup A

a. Wrist Twist : Putaran pergelangan tangan berada didekat akhir jangkauan, maka diberi nilai 1

Tabel 4.14 RULA skor grup A posisi 2B

\begin{tabular}{|c|c|c|c|c|c|c|c|c|c|}
\hline \multirow{5}{*}{$\begin{array}{l}\text { Lengan } \\
\text { atas }\end{array}$} & \multirow{5}{*}{$\begin{array}{l}\text { Lengan } \\
\text { bawah }\end{array}$} & \multicolumn{8}{|c|}{ Pergelangan tangan } \\
\hline & & \multicolumn{2}{|c|}{1} & \multicolumn{2}{|c|}{2} & \multicolumn{2}{|c|}{3} & \multicolumn{2}{|c|}{4} \\
\hline & & \multirow{2}{*}{\multicolumn{2}{|c|}{$\begin{array}{l}\text { Wrist } \\
\text { Twist }\end{array}$}} & \multirow{2}{*}{\multicolumn{2}{|c|}{$\begin{array}{l}\text { Wrist } \\
\text { Twist }\end{array}$}} & \multirow{2}{*}{\multicolumn{2}{|c|}{$\begin{array}{l}\text { Wrist } \\
\text { Twist }\end{array}$}} & \multirow{2}{*}{\multicolumn{2}{|c|}{$\begin{array}{l}\text { Wrist } \\
\text { Twist }\end{array}$}} \\
\hline & & & & & & & & & \\
\hline & & 1 & 2 & 1 & 2 & 1 & 2 & 1 & 2 \\
\hline \multirow[t]{3}{*}{1} & 1 & 1 & 2 & 2 & 2 & 2 & 3 & 3 & 3 \\
\hline & 2 & 2 & 2 & 2 & 2 & 3 & 3 & 3 & 3 \\
\hline & 3 & 2 & 3 & 3 & 3 & 3 & 3 & 4 & 4 \\
\hline \multirow[t]{3}{*}{2} & 1 & 2 & 3 & 3 & 3 & 3 & 4 & 4 & 4 \\
\hline & 2 & 3 & 3 & 3 & 3 & 3 & 4 & 4 & 4 \\
\hline & 3 & 3 & 4 & 4 & 4 & 4 & 4 & 5 & 5 \\
\hline \multirow[t]{3}{*}{3} & 1 & 3 & 3 & 4 & 4 & 4 & 4 & 5 & 5 \\
\hline & 2 & 3 & 4 & 4 & 4 & 4 & 4 & 5 & 5 \\
\hline & 3 & 4 & 4 & 4 & 4 & 4 & 5 & 5 & 5 \\
\hline \multirow[t]{3}{*}{4} & 1 & 4 & 4 & 4 & 4 & 4 & 5 & 5 & 5 \\
\hline & 2 & 4 & 4 & 4 & $\overline{4}$ & 4 & 5 & 5 & 5 \\
\hline & 3 & 4 & 4 & 4 & 5 & 5 & 5 & 6 & 6 \\
\hline \multirow[t]{3}{*}{5} & 1 & 5 & 5 & 5 & 5 & 5 & 6 & 6 & 7 \\
\hline & 2 & 5 & 6 & 6 & 6 & 6 & 7 & 7 & 7 \\
\hline & 3 & 6 & 6 & 6 & 7 & 7 & 7 & 7 & 8 \\
\hline \multirow[t]{3}{*}{6} & 1 & 7 & 7 & 7 & 7 & 7 & 8 & 8 & 9 \\
\hline & 2 & 8 & 8 & 8 & 8 & 8 & 9 & 9 & 9 \\
\hline & 3 & 9 & 9 & 9 & 9 & 9 & 9 & 9 & 9 \\
\hline
\end{tabular}


b. Otot :Pekerja melakukan kegiatan 4 kali/menit, maka sesuai dengan penilaian otot diberi nilai 1

c. Beban/ Tenaga : Pembebanan statis < $2 \mathrm{~kg}$ atau berulang, maka diberi nilai 1

d. Total Skor postur tubuh A adalah $4+1+1=6$

Postur tubuh grup B

a. Kaki : Posisi pekerja dalam keadaan berdiri dengan berat badan terdistribusi dengan rata oleh kedua kaki, terdapat ruang gerak yang cukup untuk merubah posisi, maka diberi nilai 1

Tabel 4.15 RULA skor grup B posisi 2B

\begin{tabular}{|c|c|c|c|c|c|c|c|c|c|c|c|c|}
\hline & \multicolumn{2}{|c|}{1} & \multicolumn{2}{|c|}{2} & \multicolumn{2}{|c|}{3} & \multicolumn{2}{|c|}{4} & \multicolumn{2}{|c|}{5} & \multicolumn{2}{|c|}{6} \\
\hline & \multicolumn{2}{|c|}{$\begin{array}{c}\text { Kak } \\
\text { i }\end{array}$} & \multicolumn{2}{|c|}{$\begin{array}{c}\text { Kak } \\
\text { i }\end{array}$} & \multicolumn{2}{|c|}{$\begin{array}{c}\text { Kak } \\
\text { i }\end{array}$} & \multicolumn{2}{|c|}{$\begin{array}{c}\text { Kak } \\
\text { i }\end{array}$} & \multicolumn{2}{|c|}{$\begin{array}{c}\text { Kak } \\
\text { i }\end{array}$} & \multicolumn{2}{|c|}{$\begin{array}{c}\text { Kak } \\
\text { i }\end{array}$} \\
\hline $\begin{array}{c}\text { Lehe } \\
\text { r }\end{array}$ & 1 & 2 & 1 & 2 & 1 & 2 & 1 & 2 & 1 & 2 & 1 & 2 \\
\hline 1 & 1 & 3 & 2 & 3 & 3 & 4 & 5 & 5 & 6 & 6 & 7 & 7 \\
\hline 2 & 2 & 3 & 2 & 3 & 4 & 5 & 5 & 5 & 6 & 7 & 7 & 7 \\
\hline 3 & 3 & 3 & 3 & 4 & 4 & 5 & 5 & 6 & 6 & 7 & 7 & 7 \\
\hline 4 & 5 & 5 & 5 & 6 & 6 & 7 & 7 & 7 & 7 & 7 & 8 & 8 \\
\hline 5 & 7 & 7 & 7 & 7 & 7 & 8 & 8 & 8 & 8 & 8 & 8 & 8 \\
\hline 6 & 8 & 8 & 8 & 8 & 8 & 8 & 8 & 9 & 9 & 9 & 9 & 9 \\
\hline
\end{tabular}

b. Otot : Pekerja melakukan kegiatan 4 kali/menit, maka sesuai dengan penilaian otot diberi nilai 1

c. Beban/ Tenaga : Pembebanan statis < $2 \mathrm{~kg}$ atau berulang, maka diberi nilai 1

d. Total Skor postur tubuh B adalah $5+1+1=7$

Final score

Tabel 4.16 RULA final score posisi 2B

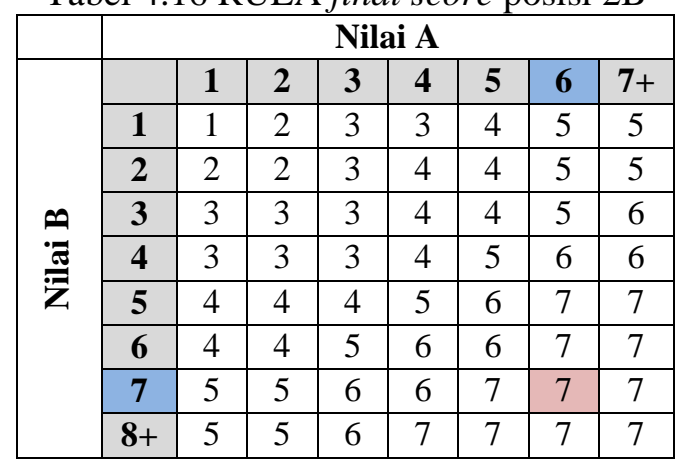

Berdasarkan tabel diatas maka Skor akhir dari penilaian RULA sebesar 7. Skor 7 masuk kedalam Action Level 4, yang menunjukkan bahwa penyelidikan dan perubahan dibutuhkan sesegera mungkin.

\section{KESIMPULAN}

Berdasarkan hasil pengolahan, analisis dan pembahasan yang telah dilakukan maka dapat ditarik kesimpulan sebagai berikut :

1. Berdasarkan analisis posturkerja menggunakan metode Rapid Upper Limb Assessment (RULA) diketahui bahwa posisi duduk operator yaitu posisi 1A, dan 1B serta posisi berdiri operator yaitu posisi $2 \mathrm{~A}$ dab $2 \mathrm{~B}$ pada saat mengambil dan memasukan adonan kedalam mesin Extruder, semuanya memiliki nilai final 7 dan action level 4 yang menunjukan menunjukkan bahwa penyelidikan dan perubahan dibutuhkan sesegera mungkin.

2. Berdasarkan analisis metode RULA dapat disimpulkan bahwa penyebab mudah pegal dan lelahnya operator yang mengoprasikan mesin Extruder adalah karena postur kerja yang kurang baik, sehingga menurunkan tingkat keteraturan operator dalam memasukan adonan kemesin yang dapat menurunkan kualitas produksi.

3. Berdasarkan perhitungan menggunakan metode RULA terhadap posisi duduk dan berdiri operator (1A, 1B, 2A, 2B) dapat disimpulkan bahwa rata-rata resiko yang ditimbulkan dari posisi duduk dan posisi berdiri operator adalah sama.

\section{DAFTAR PUSTAKA}

Afriansyah, A. 2015. Analisis Postur Tubuh Mitra Kerja PT. Sankyu Indonesia Internasional Pada Area PVC Ware House Menggunakan Metode Rapid Limb Assessment di PT. Asahimas Chemical Cilegon Banten. Laporan Tugas Akhir. Surakarta : Program Diploma 3 Hiperkes dan Keselamtan Kerja Fakultas Kedokteran Universitas Sebelas Maret Surakarta. 
Anjasmoro, T. 2017. Implementasi

Program Keselamatan dan

Kesehatan Kerja dalam Upaya

Mempertahankan Zero Accident di

PADA PT Dua Kelinci. Lapotran

Kereja Praktik Universitas Katolik

Soegijarpranata.

Masitoh, D. (2016). Analisis Postur Tubuh dengan Metode Rula Pada Pekerja Welding di Area Sub Assy PT. Fuji Technica Indonesia Karawang. Tugas Akhir Universitas Sebelas Maret.

Meliana, D. P. (2009). Aanlisis Postur Kerja dengan Metode RULA pada Bagian Pelayanan Perpustekaan USU Medan. Tugas Akhir Universitas Sumatra Utara.

McAtamney, L. and Corlett, E. N., 2004. RULA: A Survey Based Method for The Investigation of Work Related Upper Limb Disorders. Applied Ergonomics. 24 (2), 91-92.

Rafian M.A., dan Ahmad Muhsin, 2017, Analisis Beban Kerja Mekanik pada Departemen Plant dengan Metode Work Sampling, Jurnal OPSI, Vol 10, No.1, Juni 2017, available at http://jurnal.upnyk.ac.id/index.php/o psi/article/view/2165

Rinawati, S., \& Romadona. (2016). Analisis Risiko Postur Kerja pada Pekerja di Bagian Pemilahan dan Penimbangan Linen Kotor RS. X. Journal of Industrial Hygiene and Occupational Health, 39-51.

Primadi, D. P., Dyah Rachmawati L, Ahmad Muhsin, 2016, Usulan perbaikan tingkat pencahayaan pada ruang produksi guna peningkatan output produk pekerja dengan pendekatan tekcnik tata cara kerja, Jurnal OPSI, Vol. 9, No.1, Juni 2016, available at http://jurnal.upnyk.ac.id/index.php/o psi/article/view/2192 